\title{
Comunicação:
}

\section{EFEITO DO DANO MECÂNICO NA QUALIDADE FISIOLÓGICA E NA CAPACIDADE DE EXPANSÃO DE SEMENTES DE MILHO PIPOCA ${ }^{1}$}

\author{
CLESO ANTONIO PATTO PACHECO ${ }^{2}$, FLORINDO LUIZ CASTOLDI ${ }^{3}$ e EVELINE MANTOVANI ALVARENGA ${ }^{4}$
}

RESUMO - Com o objetivo de dar substilo aos produtores de sementes e/ou grãos de milho pipoca, para melhorar a qualidade fisiológica da produção, sementes da cultivar CMS-43 foram submetidas a três níveis de danificação mecânica (sem danos, com danos e com danos dobrados), e avaliadas pelos testes de germinação, vigor (condutividade elétrica) e capacidade de expansão. Os resultados demonstraram que sementes danificadas reduzem significativamente a germinação, o vigor e a capacidade de expansão das sementes. Concluiu-se que indiferente à finalidade da produção, sementes e/ou grãos, a colheita do milho pipoca precisa ser feita com o mínimo de danificação mecânica possível, para propiciar um produto com máxima qualidade.

Termos para indexação: milho pipoca, sementes, vigor, danificação mecânica, germinação e capacidade de expansão.

\section{EFFECT OF MECHANICAL DAMAGE ON PHYSIOLOGICAL QUALITY AND ON THE CAPACITY OF EXPANSION OF POPCORN SEEDS}

\begin{abstract}
These work had the purpose to give informational support to the producers of popcorn seeds and/or grains, to the improvement of physiological quality from popcorn seeds of cultivar CMS-43. The seeds were submitted to three degrees of mechanical exposure (no damage, with damage and with double damage) and it was evaluated for germination, vigor (eletrical conductivity) and expansion capacity. The results allowed to conclude that the germination, vigor and expansion capacity of the damaged popcorn seeds were significantly reduced. Finally, regarciless the purpose of production, seeds and/or grains, the harvest of popcorn must be undertaken with minimal mechanical damage, to give a product with maximum quality.

Index terms: popcorn, seeds, mechanical damage, germination, vigor and capacity of expansion.
\end{abstract}

\section{INTRODUÇÃO}

O milho pipoca devido ao tamanho reduzido e dureza de suas sementes e/ou grãos, apresenta características muito peculiares de utilização, que devem ser consideradas pelos produtores de sementes, uma vez que o aproveitamento das sobras da comercialização de sementes, não tem a mesma facilidade que o milho comum, devendo, quase que exclusivamente, serem utilizadas para o consumo humano, na forma de pipoca.

Muitos produtores já perceberam esse fato e resolveram tornar sua atividade de duplo propósito, ou seja, comercializam os grãos maiores como sementes e os menores, bem como as sobras de sementes, que não podem ser tratadas, como grãos.

\footnotetext{
'Aceito para publicação em 20.11.96.

2 Eng. Agr., MS, Pesquisador da EMBRAPA-CNPMS, Cx. Postal 151, 35701-970, Sete Lagoas, MG.

${ }^{3}$ Eng. Agr., MS, Prof. da Universidade de Passo Fundo, Cx. Postal 567, 99001-970, Passo Fundo, RS.

${ }^{4}$ Eng $^{\mathrm{a}} \mathrm{Agr}^{\mathrm{a}}$, MS, Prof ${ }^{\mathrm{a}}$ da Universidade Federal de Viçosa, Depto. de Fitotecnia, 36570-000, Viçosa, MG.
}

Uma das características mais importantes para o milho pipoca é a capacidade de expansão, estimada pela relação entre o volume de pipoca estourada e o volume de grãos utilizados para estourar, expressa pelo Índice de Capacidade de Expansão (ICE), na unidade de $\mathrm{ml} / \mathrm{ml}$. Pelo projeto de Norma de Identidade e Qualidade de Milho Pipoca, do Ministério da Agricultura e Abastecimeinto, que ainda não está em vigor, para que um milho pipoca possa ser comercializado, precisa ter no mínimo um ICE de $15 \mathrm{ml} / \mathrm{ml}$, embora as melhores pipocas tenham ICE acima de $25 \mathrm{ml} / \mathrm{ml}$.

Pacheco et al. (1992) trabalharam com amostras de 29 marcas comerciais de pipoca coletadas em todo o País e estimaram um ICE médio de $15,38 \mathrm{ml} / \mathrm{ml}$ sendo que, $50 \%$ das marcas comerciais ficaram abaixo dessa média e a melhor entre as pipocas testadas foi importada da Argentina e atingiu um ICE de apenas $23,98 \mathrm{ml} / \mathrm{ml}$.

Hoseney et al. (1983) elucidaram o mecanismo de como a pipoca estoura, demonstrando a grande importância de se ter um pericarpo integro, uma vez que é essa estrutura que suporta a elevada pressão de $135 \mathrm{psi}$ (lb/pol2), a uma temperatura de $177^{\circ} \mathrm{C}$, quando o grão estoura. Se no pericarpo existirem fendas ou trincas, que não podem ser observadas a olho nú, a pressão ideal não poderá ser atingida e, conse- 
qüentemente, a pipoca não se expandirá totalmente.

Dessa forma, operações drásticas como colheita e beneficiamento podem provocar danos à qualidade fisiológica das sementes de milho pipoca, e/ou à sua capacidade de expansão, isto se requisitos como o grau adequado de umidade das sementes e a regulagem das máquinas não forem seguidos. Parece ser desejável que os cuidados, normalmente, tomados com a finalidade de minimizar os problemas de baixa germinação e vigor, provocados por danos mecânicos, sejam, também tomados, mesmo que, o produto final se destine, exclusivamente ao consumo.

Com o objetivo de dar subsídio aos produtores de sementes e/ou grãos de milho pipoca para melhorar a qualidade fisiológica e/ou física da produção, elaborou-se esse estudo inicial, para avaliar o efeito do dano mecânico na germinação, vigor e capacidade de expansão das sementes.

\section{MATERIAL E MÉTODOS}

Utilizou-se sementes de milho pipoca da população CMS-43, safra 1993, desenvolvida pelo Centro Nacional de Pesquisa de Milho e Sorgo (CNPMS-EMBRAPA), em Sete Lagoas (MG). Trabalhou-se com uma amostra de $1.200 \mathrm{~g}$, que foi classificada pelas peneiras de furos redondos acima de 5,0mm de diâmetro, proveniente de debulha manual, e dividida em três subamostras de $400 \mathrm{~g}$, que receberam os tratamentos: 1- testemunha (sem danos mecânicos); 2- com danos mecânicos e 3- com danos mecânicos dobrados, através de nenhuma, uma ou duas passagens da amostra por um debulhador elétrico de cereais, respectivamente.

As sementes foram avaliadas pelos seguintes testes:

- Teste de germinação: Utilizou-se quatro repetições de 50 sementes que foram colocadas para germinar em rolos de papel toalha, a $25^{\circ} \mathrm{C}$, com contagens ao quarto e sétimo dia (Brasil, 1992).

- Teste de condutividade elétrica: utilizou-se o métcdo descrito por Marcos Filho et al. (1987) trabalhando-se com quatro repetições de 50 sementes por tratamento. As sementes foram contadas, pesadas e colocadas em $75 \mathrm{ml}$ de água deionizada, em copos de plástico de $120 \mathrm{ml}$, dentro de um germinador regulado a $20^{\circ} \mathrm{C}$, por 24 horas. As medições foram em mili-mnhos.

- Teste da capacidade de expansão: utilizou-se quatro repetições de $30 \mathrm{ml}$ de grãos, que foram expandidas num testador oficial da capacidade de expansão de milho pipoca, do Programa de Melhoramento de Milho do CNPMS/ EMBRAPA, na temperatura de $237^{\circ} \mathrm{C}$, mantida constante através de um termostato, por quatro minutos. $\mathrm{O}$ índice de capacidade de expansão foi obtido dividindo-se o volume de pipoca estourada, pelo volume de grãos utilizados.
- Determinação do grau de umidade: foi realizada em duas amostras, retiradas antes da aplicação dos tratamentos pelo método da estufa a $105^{\circ} \mathrm{C}$ (Brasil, 1992).

Foram analisadas estatísticamente, as características: porcentagem de germinação, índice de capacidade de expansão e vigor. Utilizou-se o delineamento inteiramente ao acaso, com quatro repetições. Realizou-se, também, as determinações das correlações simples (r) entre as três características, segundo metodologia descrita por Hoffmann \& Vieira (1987).

\section{RESULTADOS E DISCUSSÃO}

O resumo da análise de variância constante da Tabela 1 mostra que foram encontradas diferenças estatísticas para todas as características analisadas, pelo teste $\mathrm{F}$ a $5 \%$ de probabilidade.

TABELA 1. Resumo da análise de variância para germinaçã (G), índice de capacidade de expansão (ICE) e condutividade elétrica (vigor), de sementes de milho pipoca submetidas a diferentes níveis de danificação mecânica. Viçosa, MG. 1996.

\begin{tabular}{lcccc}
\hline F.V. & G.L. & \multicolumn{3}{c}{ Q.M. } \\
\cline { 3 - 5 } & & $\begin{array}{c}\text { G } \\
(\%)\end{array}$ & $\begin{array}{c}\text { ICE } \\
(\mathrm{ml} / \mathrm{ml})\end{array}$ & $\begin{array}{c}\text { Vigor } \\
(\text { mili-mnhos } / g) \times 100\end{array}$ \\
\hline Tratamentos. & 2 & $56,3336^{*}$ & $77,4886^{*}$ & $0,85180^{*}$ \\
Resíduo & 9 & 13,1112 & 1,2728 & 0,01858 \\
\hline Total & 11 & - & - & - \\
\hline C.V.(\%) & & 4,28 & 7,03 & 10,82 \\
\hline
\end{tabular}

* Significativo a $5 \%$ de probabilidade.

Na Tabela 2 observa-se que, embora os tratamentos tenham afetado todas as características, a germinação foi a que demonstrou menos o efeito imediato da danificação mecânica e só apresentou diferença significativa entre sementes sem danificação mecânica e sementes com danificação mecânica dobrada. Confirmando que essa característica, pelas condições especiais em que as sementes foram colocadas para germinar, não é uma boa indicadora do estado real das mesmas, como já demonstrado em experimentos realizados em várias outras espécies (Toledo \& Marcos Filho, 1977). A Tabela 2, mostra que houve diferença significativa entre a testemunha e as sementes com danificação mecânica.

$\mathrm{O}$ índice de capacidade de expansão (ICE), também sofreu uma redução drástica em função da danificação mecânica (Tabela 2). É interessante relatar a ineficiência de uma avaliação visual da danificação mecânica, após a passagem 
das subamostras pelo debulhador de cereais, uma vez que chegou-se a duvidar da eficiência dos tratamentos, por que não se podia distinguir visualmente um do outro. No entanto, as sementes com danos mecânicos dobrados, embora com uma germinação de $88 \%$, deveriam ser desqualificadas para comercialização como milho pipoca, por terem apresentado um ICE abaixo do limite previsto na legislação.

TABELA 2. Médias de germinação (G), índice de capacidade de expansão (ICE) e condutividade elétrica (vigor), de sementes de milho pipoca submetidas a diferentes níveis de danificação mecânica. Viçosa, MG. 1996.

\begin{tabular}{|c|c|c|c|}
\hline $\begin{array}{c}\text { Niveis de danificação } \\
\text { mecânica }\end{array}$ & $\begin{array}{c}G \\
(\%)\end{array}$ & $\begin{array}{c}\text { ICE } \\
(\mathrm{ml} / \mathrm{ml})\end{array}$ & $\begin{array}{c}\text { Vigor } \\
(\text { mili-mnhos/g) } \times 100\end{array}$ \\
\hline SEM & $95,50 a^{*}$ & $20,83 \mathrm{a}$ & $0,7648 a$ \\
\hline $\mathrm{COM}$ & $91,50 \mathrm{ab}$ & $15,17 b$ & $1,3376 b$ \\
\hline 'OBRADA & $88,00 \mathrm{~b}$ & $12,17 \mathrm{c}$ & $1,6779 c$ \\
\hline Média & 91,66 & 16,06 & 1,2601 \\
\hline
\end{tabular}

* Médias seguidas das mesmas letras dentro da mesma coluna, não diferem estatisticamente entre si pelo teste de Tukey, a $5 \%$ de probabilidade.

Observando-se o teste de médias para o ICE na Tabela 2, nota-se uma redução mais intensa das sementes sem danos para as sementes com danos, do que deste tratamento para as sementes com danos dobrados. Considerando as sementes sem danos como $100 \%$, as reduções foram de $27,17 \%$ para as sementes com danos e de $41,57 \%$ para as sementes com danos dobrados, o que está de acordo com os resultados relatados por Hoseney et al. (1983). Esses autores trabalharam com níveis conhecidos de danos no pericarpo e mostraram uma grande redução do ICE em sementes com pequenos danos, e reduções menores em sementes com danos de maior extensão.

Os resultados da condutividade elétrica refletiram, também, a queda na qualidade das sementes, mas em sentido contrário ao descrito para o ICE. O maior aumento dos valores de condutividade ocorreu das sementes sem danos para as sementes com danos do que deste tratamento para as sementes com danos dobrados.

A possível relação entre as características ou métodos avaliados nesse trabalho, foi estudada através de correlações simples e podem ser vistas na Tabela 3. Embora todas as correlações simples ( $\mathbf{r}$ ) tenham sido significativas pelo teste $\mathbf{t}$ a $5 \%$ de probabilidade, deve-se destacar a magnitude do $r=-0,8866$ entre o ICE e a condutividade elétrica, o que de certa forma poderia ser esperado, uma vez que todos os testes foram realizados imediatamente após a aplicação da danificação mecânica. É provável que, tanto no ICE quanto na condutividade elétrica, os danos é que permitem o vazamen- to de pressão e de solutos citoplasmáticos para o meio.

É interessante observar ainda que o $r=0,7906$ entre a germinação e o ICE indica que este, pela rapidez com que pode ser realizado, poderia ser considerado um bom preditor, também, da germinação. Entretanto, alguns estudos tem evidenciado que a determinação do ICE é sensível a umidade das sementes, atingindo um máximo entre 12 e $15 \%$ e decrescendo fora desse intervalo (Hoseney et al., 1983) e, ainda, que sementes que tiveram sua viabilidade reduzida, ou até mesmo o embrião morto, mas, que foram preservadas quanto a integridade do pericarpo, mantiveram quase intacta sua capacidade de expansão (Machado \& Zinsly, 1978).

TABELA 3. Correlações simples entre germinação (G), índice de capacidade expansão (ICE) e condutividade elétrica (vigor) de sementes de milho pipoca submetidas a diferentes níveis de danificação mecânica. Viçosa, MG. 1996.

\begin{tabular}{lccc}
\hline & G & ICE & Vigor \\
\hline G & 1,0000 & $0,7906^{*}$ & $-0,5803^{*}$ \\
ICE & & 1,0000 & $-0,8866^{*}$ \\
Vigor & & & 1,0000 \\
\hline
\end{tabular}

* Significativo pelo teste $\mathrm{t}$ a $5 \%$ de probabilidade

Embora a utilização do ICE, com a finalidade de inferir sobre a qualidade fisiológica das sementes de milho pipoca, necessite ser melhor estudada, os resultados desse trabalho vem confirmar que o uso desse índice é fundamental para o monitoramento e manutenção da qualidade dos grãos de mitho pipoca, ou a pipocabilidade, como poderia ser melhor chamado. Contudo, ficou evidente que para esse tipo de milho a distinção entre sementes e grãos poderia ficar quase que restrita aos aspectos genéticos e de utilização do material produzido, uma vez que a presença de um pericarpo intacto, que é um certificado de garantia da integridade físicafisiológica da semente, se mostrou até mais importante para o consumo do que para o plantio, na situação deste trabalho, ou seja, utilizando-se sementes novas.

$\mathrm{O}$ grau de umidade médio das sementes nesse estudo foi de 11,3\%; nesse nível são mais comuns os danos por quebra ou trinca. Estudos realizados com outras faixas de umidade poderão esclarecer melhor esse assunto.

\section{CONCLUSÕES}

- Os danos mecânicos provocados nas sementes afetaram o vigor;

- a danificação mecânica provoca redução drástica no índice de capacidade de expansão; 
- o indice de capacidade de expansão pode ser um auxíliar na avaliação da qualidade fisiológica da semente nova de milho pipoca;

- seja para consumo "in natura", ou seja para produção de sementes, a colheita do milho pipoca deve ser feita com o máximo cuidado, para minimizar os danos mecânicos e, assim, propiciar um produto com máxima qualidade fisiológica e/ou capacidade de expansão.

\section{AGRADECIMENTOS}

Os autores agradecem ao Centro Nacional de Pesquisa de Milho e Sorgo (CNPMS/EMBRAPA), na pessoa do pesquisador Dr. Sidney Netto Parentoni, pelo fornecimento das sementes e ao operário rural Elísio (Peninha), pela realização dos testes de expansão.

\section{REFERÊNCIAS}

BRASIL. Ministério da Agricultura e Reforma Agrária. Regras para análise de sementes. Brasília, SNDA.DNDV/CLAV, 1992. 365p.

HOSENEY, R.C.; ZELEZNAK, K. \& ABDELRAHMAN, A. Mechanism of popcorn popping. Journal of Cereal Science. v.1,p.43-52. 1983

MACHADO, J.A \& ZINSLY, J.R. Milho pipoca. In: PATERNIANI, E. Melhoramento e produção do milho no Brasil. ed. Campinas: Fundação Cargill e Piracicaba: ESALQ, 1978. $650 \mathrm{p}$.

MARCOS FILHO, J.;CÍCERO, S.M. \& DA SILVA, W.R. Avaliação da qualidade das sementes. Piracicaba: FEALQ, 1987. 230p.

PACHECO, C.A.P.; GARCIA, J.C.; OLIVEIRA, A.C. \& MONTEIRO, J.A. Avaliação de milho pipoca de diferentes marcas comerciais disponiveis no mercado brasileiro. In: CONGRESSO NACIONAL DE MILHO E SORGO, 19, Porto Alegre,1992.

HOFFMANN, R. \& VIEIRA, S. Análise de regressão: uma introdução à econometria. São Paulo: Hucitec, 1987. 379p.

TOLEDO, F.F.; MARCOS FILHO, J. Manual das sementes - tecnologia da produção. São Paulo: Agron. Ceres, 1977. 224p. 